\title{
BMJ Open SOS! Summer of Smoke: a retrospective cohort study examining the cardiorespiratory impacts of a severe and prolonged wildfire season in Canada's high subarctic
}

Courtney Howard (D , ${ }^{1}$ Caren Rose, ${ }^{2}$ Warren Dodd, ${ }^{3}$ Katherine Kohle, ${ }^{4}$ Craig Scott, ${ }^{5}$ Patrick Scott, ${ }^{6}$ Ashlee Cunsolo, ${ }^{7}$ James Orbinski ${ }^{8}$

To cite: Howard C, Rose C, Dodd W, et al. SOS! Summer of Smoke: a retrospective cohort study examining the cardiorespiratory impacts of a severe and prolonged wildfire season in Canada's high subarctic. BMJ Open 2021;11:e037029. doi:10.1136/ bmjopen-2020-037029

- Prepublication history and additional material for this paper are available online. To view these files, please visit the journal online (http://dx.doi. org/10.1136/bmjopen-2020037029).

Received 09 April 2020 Revised 30 October 2020 Accepted 10 November 2020

D) Check for updates

(C) Author(s) (or their employer(s)) 2020. Re-use permitted under CC BY-NC. No commercial re-use. See rights and permissions. Published by BMJ.

For numbered affiliations see end of article.

\section{Correspondence to}

Dr Courtney Howard;

doctorswithinborderscanada@ gmail.com

\section{ABSTRACT}

Objectives To determine healthcare service utilisation for cardiorespiratory presentations and outpatient salbutamol dispensation associated with 2.5 months of severe, unabating wildfire smoke in Canada's high subarctic.

Design A retrospective cohort study using hospital, clinic, pharmacy and environmental data analysed using Poisson regression.

Setting Territorial referral hospital and clinics in Yellowknife, Northwest Territories, Canada.

Participants Individuals from Yellowknife and surrounding communities presenting for care between 2012 and 2015.

Main outcome measures Emergency room (ER) presentations, hospital admissions and clinic visits for cardiorespiratory events, and outpatient salbutamol prescriptions

Results The median 24-hour mean particulate matter $\left(\mathrm{PM}_{25}\right)$ was fivefold higher in the summer of 2014 compared with 2012, 2013 and 2015 (median $=30.8 \mu \mathrm{g} /$ $\mathrm{m}^{3}$ ), with the mean peaking at $320.3 \mu \mathrm{g} / \mathrm{m}^{3}$. A $10 \mu \mathrm{g} /$ $\mathrm{m}^{3}$ increase in $\mathrm{PM}_{2.5}$ was associated with an increase in asthma-related (incidence rate ratio (IRR) $(95 \% \mathrm{Cl})$ : $1.11(1.07,1.14))$ and pneumonia-related ER visits (IRR $(95 \% \mathrm{Cl}): 1.06(1.02,1.10))$, as well as an increase in chronic obstructive pulmonary disease hospitalisations (IRR (95\% Cl): 1.11 (1.02, 1.20). Compared with 2012 and 2013, salbutamol dispensations in 2014 increased by $48 \%$; clinic visits for asthma, pneumonia and cough increased; ER visits for asthma doubled, with the highest rate in females, in adults aged $\geq 40$ years and in Dene people, while pneumonia increased by $57 \%$, with higher rates in males, in individualsaged $<40$ years and in Inuit people. Cardiac variables were unchanged.

Conclusions Severe wildfires in 2014 resulted in extended poor air quality associated with increases in health resource utilization; some impacts were seen disproportionately among vulnerable populations, such as children and Indigenous individuals. Public health advisories asking people to stay inside were inadequately protective, with compliance possibly impacted by the prolonged exposure. Future research should investigate use of at-home air filtration systems, clean-air shelters
Strengths and limitations of this study

- This study investigates the respiratory health impacts of one of the most severe and prolonged episodes of wildfire smoke that has been examined in the literature base, with impacts on respiratory health measured through analysis of records in a remote, well-defined catchment area in terms of emergency department and clinic services.

- The usually pristine air quality of Yellowknife, Northwest Territories and the surrounding communities means that background air pollution does not confound the results as it does in most other studies.

- The sister arm of this study represents an analysis of 30 interviews which explored the lived experience of community members during the summer of smoke, insights from which help to inform the analysis of this study, facilitating practical recommendations for improved public health and clinical management of future smoky summers.

- This study was unable to estimate the inflow or outflow of potential patients from the region as the smoky summer progressed, although qualitative information indicates that at least some severely impacted people left the area.

- Records were not available for daily outpatient salbutamol dispensations or inpatient salbutamol dispensation, so estimates of the salbutamol used in the region are limited to monthly community dispensations.

and public health messaging which addresses mental health and supports physical activity.

\section{INTRODUCTION}

Extreme wildfires linked to altered temperature and precipitation patterns are increasing in many parts of the world as the climate changes, with major consequences for planetary health, including its biospheric and human subsystems. ${ }^{1-3}$ Human health impacts 
of fire include death, trauma, major burns, ${ }^{4}$ anxiety and post-traumatic stress disorder. ${ }^{5}{ }^{6}$ Wildfire smoke also travels vast distances, ${ }^{1}$ exposing populations to a complex mixture of the products of combustion, ${ }^{7}$ most commonly measured as either particulate matter less than 2.5 microns in diameter $\left(\mathrm{PM}_{2.5}\right)$ or less than 10 microns in diameter $\left(\mathrm{PM}_{10}\right){ }^{1}$ Exposure to wildfire smoke has been shown to increase asthma reliever medication use, ${ }^{89}$ and is consistently associated with exacerbations of asthma and chronic obstructive pulmonary disease (COPD), with indications of an association with low birth weight and growing support for an association with respiratory tract infections and all-cause mortality. ${ }^{1}$ Evidence relating smoke exposure to cardiovascular impacts is inconsistent. ${ }^{1{ }^{10}}$ Studies on the long-term impacts of severe acute exposure are minimal, but indicate concern; for example, a group of Rhesus monkeys exposed to wildfire smoke as infants had reduced lung function during adolescence, ${ }^{11}$ and recent evidence shows that mean prenatal exposure to air pollution related to the 1997 Indonesian forest fires was associated with a half SD decrease in height-for-age metrics at age $17 .{ }^{12}$

Greenhouse gas emissions from wildfires are also significant, meaning that the fires themselves have the potential to speed climate change, with further adverse impacts on planetary health. ${ }^{2}$ Current wildfire-related public health approaches were conceived to protect populations during relatively shorter and less-severe wildfire seasons: it is necessary to re-evaluate the effectiveness and tolerability of health interventions as wildfires intensify. As climate change progresses in the Anthropocene, both biospheric ecosystems and human society must prepare for an increasingly disturbed future of forests in order to anticipate and minimise health impacts. ${ }^{313}$

Yellowknife, the capital of Canada's high-subarctic Northwest Territories (NWT), has experienced a $2.5^{\circ} \mathrm{C}$ increase in annual average temperature over the past 70 years. ${ }^{14}$ In 2014 and 2015, moderate-to-severe drought conditions contributed to the worst and second-worst fire seasons on record in the NWT, ${ }^{1516}$ leading in 2014 to 385 fires which impacted 3.4 million hectares of forest ${ }^{15}$ and two and a half months of unabating wildfire smoke exposure for residents of Yellowknife and the adjacent Indigenous communities of N'Dilo and Dettah. Residents also endured months of closed highways, isolation indoors and reduced physical activity, as well as stress and worry associated with a constant state of evacuation readiness, with people of the Dehcho Dene from the Ka'a'gee Tu First Nation near Kakisa Lake, south of Yellowknife, actually evacuated. ${ }^{217}$ Some NWT residents referred to this season as 'the lost summer'. ${ }^{17}$

The Summer of Smoke (SOS) project was designed to generate a holistic view of planetary health impacts of the 2014 NWT wildfires by pairing quantitative and qualitative perspectives in order to inform adaptation to future smoke-filled summers. Drawing on the quantitative data from the overarching project, this article analyses and describes the air quality exposure in Yellowknife, Dettah and N'Dilo during the summers of 2014 and surrounding years; assesses the risk of cardiorespiratory health encounters associated with increasing particulate matter; and examines changes in salbutamol dispensation and health resource utilisation compared with other years. Few studies examining severe exposures of longer than a few weeks exist in the literature and almost no available research combines quantitative and qualitative analysis to determine the overall tolerability of a given smoke exposure for a community. This study's subarctic setting puts it at the leading edge of climate-related impacts and the project's approach provides insights on interactions between and among smoke exposure, physical health, mental health and health systems that can inform primary care and public health adaptations to the increasingly severe wildfire seasons that can be expected as the Anthropocene advances.

\section{METHODS}

\section{Project Structure and Context}

SOS is a community-based, interdisciplinary projectthat investigated the impacts of the NWT's 2014 extreme wildfire season on the health andwell-bein of people in four primary communities: Yellowknife (population $=20497$, $24 \%$ Indigenous); and the near $100 \%$ Indigenous Yellowknives Dene communities of N'Dilo (adjacent to Yellowknife, population $=345$ ) and Dettah (across a bay from Yellowknife, population=252); and the Ka'a'gee Tu First Nation in Kakisa (southwest around Great Slave Lake from Yellowknife, population=36) ${ }^{18}$ Many Indigenous individuals in this area maintain a strong connection to the land, continuing traditional hunting, fishing and plant-gathering practices. ${ }^{19}$

\section{Study partners}

This project was initiated by representatives of the Yellowknives Dene First Nation, Yellowknife physicians and Ecology North (an environmental non-governmental organisation in Yellowknife), and carried out in partnership with the Dene of the Dehcho from the Ka'a'gee Tu First Nation, with support from external academic collaborators.

\section{Patient and public involvement}

Representatives of the Yellowknives Dene and the Ka'a'gee Tu First Nation helped to define the overall project structure from the outset. They contributed to the decision to include both quantitative and qualitative elements in the larger project ${ }^{17}$ in order to evaluate the impact of wildfires on traditional land-based activities and overall wellness, with the goal of optimally informing practical adaptation policies. They were partners on the grant application, co-defined the centrality of respiratory issues to the study and collaboratively generated the interview guide and community engagement strategy. Decision-makers, business leaders and public health leaders in Yellowknife were also engaged and interviewed. Plain language summaries 
Table 1 The 24-hour mean $\mathrm{PM}_{2.5}$ and $\mathrm{PM}_{10}$ from 15 June to 31 August

\begin{tabular}{|c|c|c|c|c|}
\hline & $\begin{array}{l}\text { Median } \mathrm{PM}_{2.5}(\mathrm{Q} 1, \mathrm{Q} 3)^{*} \\
\mu \mathrm{g} / \mathrm{m}^{3}\end{array}$ & $\begin{array}{l}\text { Maximum } \mathrm{PM}_{2.5} \\
\mu \mathrm{g} / \mathrm{m}^{3}\end{array}$ & $\begin{array}{l}\% \text { of days with } \\
\mathrm{PM}_{2.5} \geq 25 \mu \mathrm{g} / \mathrm{m}^{3}\end{array}$ & $\begin{array}{l}\text { Median } \mathrm{PM}_{10} \\
(\mathrm{Q} 1, \mathrm{Q} 3) \mathrm{\mu g} / \mathrm{m}^{3}\end{array}$ \\
\hline 2012 & 6.2 (5.6 to 8.9$)$ & 65.7 & 4 (3 days) & 13.3 (9.5 to 17.9$)$ \\
\hline 2014 & 30.8 (16.2 to 85.0$)$ & 320.3 & 55 (43 days) & 43.8 (26.5 to 100.7$)$ \\
\hline 2015 & 6.4 (4.6 to 11.5$)$ & 99.6 & 12 (9 days) & 14.9 (10.3 to 28.8$)$ \\
\hline
\end{tabular}

${ }^{*}$ Q1 - first quartile; Q3 - third quartile.

and videos were prepared to facilitate effective communication of initial findings and were presented at community gatherings. A final plain language policy paper and three short video vignettes on the community-level adaptive interventions identified as being most likely to improve health during future fire years (clean air shelters with recreation activities, active fire preparation and attention to both respiratory health and eco-anxiety) were prepared in association with the study's coordinators and distributed to communities across the NWT.

\section{STATISTICAL ANALYSIS \\ Descriptive \\ Air quality}

Data for particulate matter $\left(\mathrm{PM}_{2.5}\right.$ and $\left.\mathrm{PM}_{10}\right)$ and covariates (humidity and temperature) from 15 June to 31 August 2012-2015 were obtained from the Yellowknife Air Quality Monitoring station, which provides information relevant to Yellowknife ${ }^{20}$ as well as N'Dilo and Dettah, both of which are approximately $3 \mathrm{~km}$ from the outskirts of Yellowknife. The 24-hour mean $\mathrm{PM}_{2.5}$ levels were examined for each study year, and the proportion of study days each year where the 24-hour mean $\mathrm{PM}_{2.5}$ exceeded the WHO recommended 24-hour mean air quality threshold of $25 \mu \mathrm{g} / \mathrm{m}^{3}$ was determined. ${ }^{21} \mathrm{PM}_{10}$ was described to facilitate comparison with other studies (table 1).

\section{Risk of particulate matter for emergency room visits and hospital} admissions

Routinely collected administrative data from emergency room (ER) visits and hospital admissions for 15 June 15-31 August 2012-2015 was retrieved from Stanton Territorial Hospital (referral hospital for the NWT and the Kitikmeot). Cause-specific diagnoses using the most responsible diagnosis were coded using International Statistical Classification of Diseases and Related Health Problems, 10th Revision, Canada (ICD-10-CA) codes for cardiorespiratory diagnoses (see footnote of table 2). Administrative records included information on age, sex and ethnicity (non-Indigenous and Indigenous groups: Inuit, Dene, Métis). Indigenous/non-Indigenous status was determined from NWT personal health numbers. Patients from out of territory were considered to be nonIndigenous. Population estimates by age, sex and ethnicity were obtained from the Territorial Bureau of Statistics. ${ }^{18}$
Generalised linear Poisson regression models were used to estimate the effect of daily $\mathrm{PM}_{2.5}$ on population rates of cardiorespiratory ER visits and hospital admissions. Subgroup analyses for asthma, pneumonia and COPD were conducted by age, sex and ethnicity. We hypothesised that the effect of $\mathrm{PM}_{2.5}$ on asthma might change during the summer of 2014 as population members fled the territory or filled asthma medications. To assess this, we examined the relationship of $\mathrm{PM}_{2.5}$ with asthma in early summer (15 June 15-31 July 2014) and late summer (1 August-31 August 2014). All models were adjusted for age, sex, ethnicity, day of week, humidity and temperature. Goodness of fit and Poisson regression assumptions were checked for all models.

The primary particulate matter exposure was assessed using a 2-day average 24-hour mean $\mathrm{PM}_{2.5}$ (ie, average of previous and current day 24-hour mean $\mathrm{PM}_{2.5}$ levels), as per previously published literature that found it to be more highly associated with clinical outcomes than a 1-day 24-hour mean. ${ }^{810}$ Sensitivity analyses were conducted for primary outcomes using 1-day 24-hour mean $\mathrm{PM}_{2.5}$ and $\mathrm{PM}_{10}$ exposures. All incidence rate ratios were calculated for a $10 \mu \mathrm{g} / \mathrm{m}^{3}$ increase in measured $\mathrm{PM}_{2.5}$.

\section{Health resource utilisation during the summer of 2014}

To assess the burden of wildfire smoke on health resources in 2014 compared with non-extreme fire years (20122013), we examined salbutamol dispensations, clinic visits for respiratory symptoms and diagnoses, as well as cardiorespiratory ER visits and hospital admissions. 2015 was the NWT's second-worst fire season on-record, and was thus not used as part of the baseline, but is included to examine whether health utilisation decreased after 2014.

Aggregate monthly salbutamol dispensation information was gathered from Yellowknife's five outpatient pharmacies (daily data and inpatient dispensations were unavailable). An equivalency between metered-dose inhaler (MDI) and nebulised salbutamol was generated using similar equivalencies to those used in a Cochrane review $^{22}$ (see online supplemental appendix) and calculations were done equating one outpatient dose to two puffs by MDI or $833 \mathrm{mcg}$ of nebulised salbutamol. The correlation with the proportion of days where the 24-hour mean $\mathrm{PM}_{2.5}$ was greater than the $\mathrm{WHO}$ recommended air quality threshold was determined. 
Table 2 Adjusted risk of cardiorespiratory emergency room visits and inpatient hospital admissions per $10 \mu \mathrm{g} / \mathrm{m}^{3}$ increase in 2-day averaged 24-hour mean $\mathrm{PM}_{2.5}$. All models adjusted for age, sex, ethnicity, day of week, humidity and temperature.

\begin{tabular}{|c|c|c|}
\hline Outcome & $\begin{array}{l}\text { Emergency room visits } \\
\text { Incidence rate ratio }(95 \% \mathrm{Cl})\end{array}$ & $\begin{array}{l}\text { Inpatient hospital admissions } \\
\text { Incidence rate ratio }(95 \% \mathrm{CI})\end{array}$ \\
\hline Cardiovascular basket ${ }^{*}$ & 0.99 (0.94 to 1.04$)$ & $1.04(0.98,1.10)$ \\
\hline Respiratory basket ${ }^{\star}$ & 1.03 (1.01 to 1.05$)$ & 1.03 (0.98 to 1.07$)$ \\
\hline \multicolumn{3}{|l|}{ Asthma ${ }^{\star *}$} \\
\hline ALL & 1.11 (1.07 to 1.14$)$ & 1.11 (0.99 to 1.25$)$ \\
\hline Male & 1.12 (1.08 to 1.17$)$ & 1.20 (1.01 to 1.43$)$ \\
\hline Female & 1.07 (1.03 to 1.12$)$ & 1.05 (0.86 to 1.27$)$ \\
\hline Inuit & 1.11 (1.04 to 1.19$)$ & 1.01 (0.78 to 1.29$)$ \\
\hline Dene & 1.09 (1.00 to 1.19$)$ & $\mathrm{NE}$ \\
\hline Non-Indigenous & 1.10 (1.06 to 1.15$)$ & 1.27 (1.06 to 1.51$)$ \\
\hline Age $<5$ years & 0.99 (0.73 to 1.35$)$ & 0.97 (0.36 to 2.61$)$ \\
\hline Age 5-19 years & 1.07 (1.01 to 1.14$)$ & 1.12 (0.97 to 1.29$)$ \\
\hline Age $20-39$ years & 1.09 (1.04 to 1.14$)$ & 0.98 (0.71 to 1.36$)$ \\
\hline Age $40-59$ years & 1.12 (1.07 to 1.18$)$ & NE \\
\hline Age $\geq 60$ years & 1.11 (0.96 to 1.30$)$ & NE \\
\hline \multicolumn{3}{|l|}{ Pneumonia** } \\
\hline ALL & 1.06 (1.02 to 1.10$)$ & 1.02 (0.94 to 1.11$)$ \\
\hline Male & 1.09 (1.04 to 1.14$)$ & 1.04 (0.95 to 1.15$)$ \\
\hline Female & 1.00 (0.92 to 1.08$)$ & 0.97 (0.82 to 1.14$)$ \\
\hline Inuit & $1.10(1.06$ to 1.16$)$ & 1.09 (0.99 to 1.19) \\
\hline Dene & NE & 0.84 (0.57 to 1.23$)$ \\
\hline Non-Indigenous & 0.97 (0.87 to 1.09 ) & 0.60 (0.26 to 1.37$)$ \\
\hline Age $<5$ years & 1.13 (1.06 to 1.20$)$ & 1.12 (1.01 to 1.25$)$ \\
\hline Age 5-19 years & 1.09 (0.99 to 1.19$)$ & 0.98 (0.79 to 1.22$)$ \\
\hline Age $20-39$ years & 0.95 (0.78 to 1.14$)$ & $\mathrm{NE}$ \\
\hline Age $40-59$ years & 0.96 (0.84 to 1.10$)$ & 1.10 (0.92 to 1.32$)$ \\
\hline Age $\geq 60$ years & 1.06 (0.99 to 1.14$)$ & 0.80 (0.57 to 1.13$)$ \\
\hline \multicolumn{3}{|c|}{ Chronic obstructive pulmonary disease ${ }^{*} \dagger$} \\
\hline ALL & 0.97 (0.89 to 1.06$)$ & $1.11(1.02$ to 1.20$)$ \\
\hline Male & 0.99 (0.90 to 1.09$)$ & 1.12 (1.02 to 1.23$)$ \\
\hline Female & 0.89 (0.70 to 1.14$)$ & 1.09 (0.91 to 1.31$)$ \\
\hline Inuit & 0.51 (0.18 to 1.44$)$ & 1.15 (1.01 to 1.31$)$ \\
\hline Dene & $0.16(0.004$ to 6.33$)$ & $1.17(1.04$ to 1.33$)$ \\
\hline Non-Indigenous & 1.00 (0.91 to 1.09$)$ & $0.66(0.34$ to 1.27$)$ \\
\hline Age $40-59$ years & 0.81 (0.56 to 1.19$)$ & 0.95 (0.64 to 1.42$)$ \\
\hline Age $\geq 60$ years & 0.99 (0.90 to 1.08$)$ & 1.12 (1.03 to 1.22$)$ \\
\hline
\end{tabular}

*International Statistical Classification of Diseases and Related Health Problems, 10th Revision, Canada (ICD-10-CA) codes: all cardiac (I00-I52); all respiratory (J00-J99); asthma (J45-J46); pneumonia (J12-J18); chronic obstructive pulmonary disease (J44).

†Chronic obstructive pulmonary disease only in age $\geq 40$ years.

NE, not estimable.

Deidentified data on clinic visits for respiratory symptoms and diagnoses were retrieved using the practice search function of the Yellowknife Health and Social Services (YHSSA) Wolf electronic medical record by YHSSA employees on the research team. Visits for upper respiratory tract infections, conjunctivitis, bronchitis, cough, asthma, COPD, pneumonia and allergy were searched using standard case insensitive terms. $\chi^{2}$ tests were performed to assess differences in the number of symptoms and diagnoses by year. 


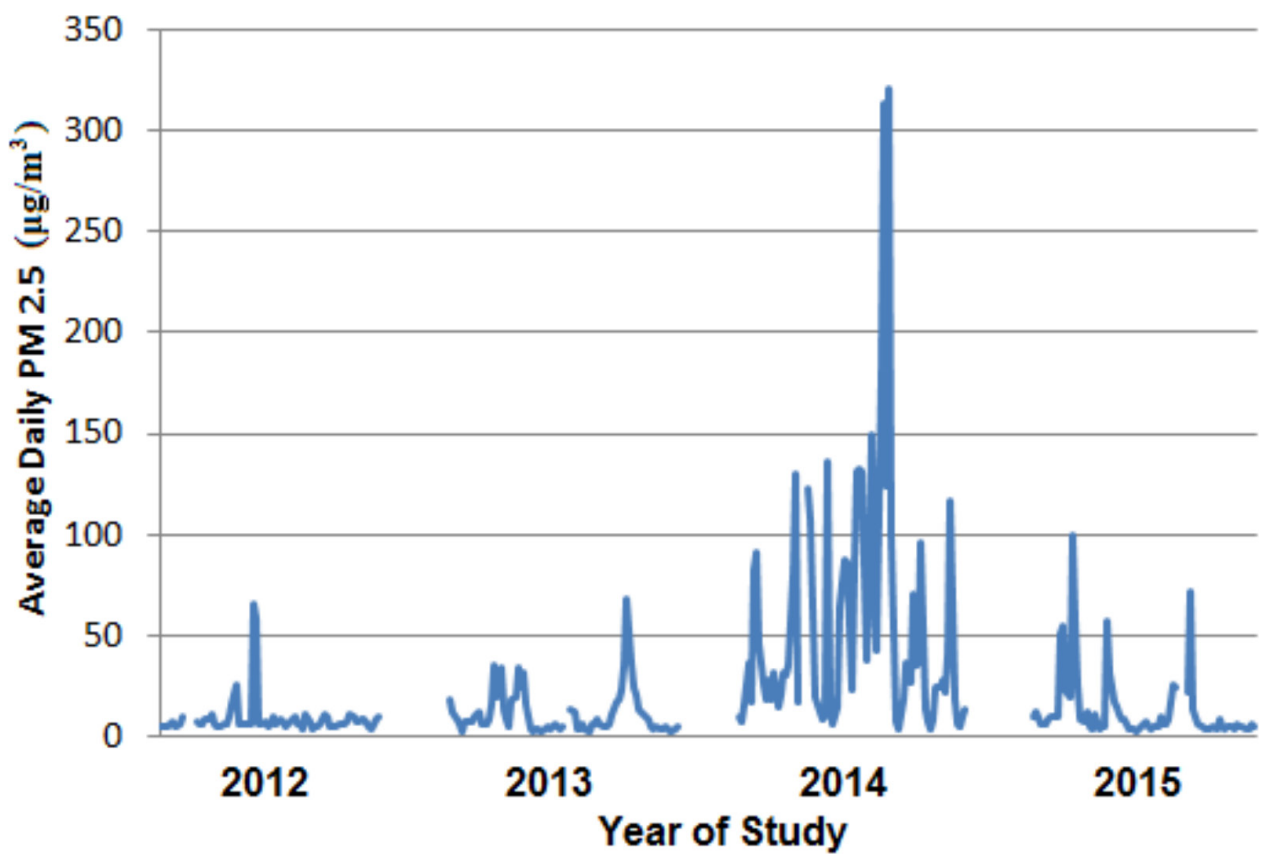

Figure 1 The 24-hour mean $\mathrm{PM}_{2.5}$ from Yellowknife Air Quality Station on 15 June-31 August 2012-2015.

To determine changes in ER visits for cardiorespiratory diagnoses in 2014 compared with 2012-2013, we calculated standardised incidence ratios (SIRs). Territorial statistics demonstrated that there was no significant change in the study population (Yellowknife, Dettah, N'Dilo) between 2012 and 2015. ${ }^{18}$ Therefore, we calculated the expected number of ER visits by averaging the number of visits in 2012 and 2013. To calculate the SIRs, we divided the observed number of ER visits in 2014 by the expected number of visits.

All analyses were performed using SAS V.9.4.

\section{RESULTS}

Figure 1 and table 1 show the distribution of the 24-hour mean $\mathrm{PM}_{2.5}$ by year. The median 24-hour mean $\mathrm{PM}_{2.5}$ was fivefold higher in 2014 compared with 2012, 2013 and 2015 , and reached a peak of $320.3 \mu \mathrm{g} / \mathrm{m}^{3}$ on 5 August 2014 (highest hourly recorded $\mathrm{PM}_{2.5}$ that day was $873 \mu \mathrm{g} /$ ? $\mathrm{m}^{3}$ ). The maximum 24-hour mean $\mathrm{PM}_{10}$ was $350 \mu \mathrm{g} / \mathrm{m}^{3}$ on 3 August 2014 (hourly maximum that day was $772 \mu \mathrm{g} /$ $\mathrm{m}^{3}$ ). In 2014, $\mathrm{PM}_{2.5}$ levels were above the recommended WHO threshold of $25 \mu \mathrm{g} / \mathrm{m}^{3}$ for 43 days (55\%).

Spikes in $\mathrm{PM}_{25}$ in 2012, 2013 and 2015 were related to intermittent wildfires. The 2015 maximum 24-hour mean $\mathrm{PM}_{2.5}$ on $30 \mathrm{June} 2015$ was $99.6 \mu \mathrm{g} / \mathrm{m}$, lower than 2014, but higher than 2012 and 2013. Twelve per cent of days in 2015 exceeded the WHO threshold.

\section{Risk of particulate matter for cardiorespiratory emergency} department visits and hospital admissions

A $10 \mu \mathrm{g} / \mathrm{m}^{3}$ increase in 2-day average 24-hour mean $\mathrm{PM}_{2.5}$ was associated with a $3 \%$ increase in ER visits for respiratory diagnoses (incidence rate ratio (IRR) $(95 \% \mathrm{CI})$ : $1.03(1.01,1.05))$ (table 2). Sensitivity analyses show consistency using the 24-hour mean $\mathrm{PM}_{2.5}$ exposure (IRR $(95 \% \mathrm{CI}): 1.03(1.01,1.05))$ and the 24-hour mean $\mathrm{PM}_{10}$ (IRR $(95 \% \mathrm{CI}): 1.03(1.01,1.04))$. This increase in ER visits was highest for asthma $\left(11 \%\right.$ increase per $10 \mu \mathrm{g} / \mathrm{m}^{3}$ in $\mathrm{PM}_{2.5}$ : IRR (95\% CI): 1.11 (1.07, 1.14), an impact that was consistent across subgroups of age (except among children aged $<5$ years)), sex and ethnicity. Increasing $\mathrm{PM}_{2.5}$ was suggestive of increased inpatient asthma admissions overall, with strong effects seen among males and non-Indigenous persons (table 2).

$\mathrm{PM}_{2.5}$ increases were also related to ER visits for pneumonia (6\% increase per $10 \mu \mathrm{g} / \mathrm{m}^{3}$ in $\mathrm{PM}_{2.5}$ IRR (95\% CI): $1.06(1.02,1.10)$, an effect that was evident in children aged $<5$ years, males and the Inuit population, with a suggestive effect among children aged 5-19 and adults aged $\geq 60$ years (table 2 ). Pneumonia hospitalisations did not increase overall with higher $\mathrm{PM}_{2.5}$ but children aged $<5$ years did have a $12 \%$ increase in admissions per $10 \mu \mathrm{g} /$ $\mathrm{m}^{3}$ in $\mathrm{PM}_{2.5}$ IRR $(95 \% \mathrm{CI}): 1.12(1.01,1.25)$.

$\mathrm{PM}_{2.5}$ was not related to ER visits for COPD, but inpatient admissions were increased $11 \%$ per $10 \mu \mathrm{g} / \mathrm{m}^{3}$ in $\mathrm{PM}_{2.5}$ IRR $(95 \% \mathrm{CI}): 1.11(1.02,1.20)$. The effect was most noticeable among males, in the Inuit and Dene populations, and among individuals $\geq 60$ years of age.

In sensitivity analyses, an increase in $\mathrm{PM}_{2.5}$ of $10 \mu \mathrm{g} /$ $\mathrm{m}^{3}$ in the extreme fire summer of 2014 was more highly associated with an increase in asthma ER visits early in the summer (15 June-31 July (IRR (95\% CI): 1.19 (1.07, 1.32)) ) than later in the summer (1 August-31 August (IRR (95\% CI): $1.04(0.99,1.01))$ ).

No significant association was seen between $\mathrm{PM}_{2.5}$ and cardiovascular ER visits (IRR (95\% CI): 0.99 (0.84, 1.04)) or inpatient hospital admissions (IRR (95\% CI): 1.04 $(0.98,1.10))$ (table 2$)$. 


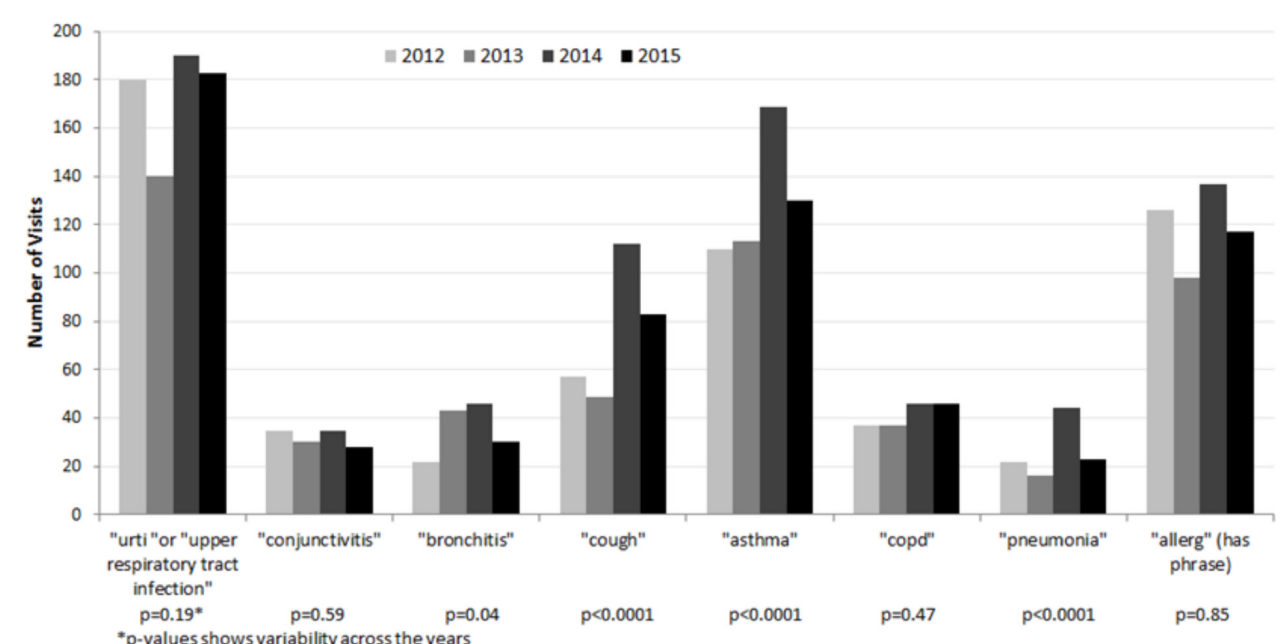

Figure 2 Yellowknife Health and Social Services primary care clinic visits for respiratory symptoms and diagnoses on 15 June31 August 2012-2015.

Pharmaceutical dispensation and health services impacts of increased smoke exposure in 2014

There was a $48 \%$ increase in dispensed outpatient doses of salbutamol in 2014 compared with 2012-2013, and this number fell in 2015 (2012: 105618 doses; 2013: 130888 doses; 2014: 175208 doses; 2015: 147738 doses). The number of salbutamol doses dispensed each summer was positively correlated with the proportion of days that $\mathrm{PM}_{2.5}$ exceeded the WHO 24-hour mean guideline value of $25 \mu \mathrm{g} / \mathrm{m}^{3}$ ( $\left.\mathrm{r}=0.89, \mathrm{p}=0.11\right)$.

Primary care clinic visits for cough and pneumonia doubled in 2014 and clinic visits for asthma increased more than 50\% compared with earlier years $(p<0.0001$ for each). Clinic visits with these presentations decreased in 2015 but remained higher than 2012/2013 levels (figure 2). There was no change seen in clinic visits for upper respiratory tract infection, conjunctivitis, bronchitis, COPD or allergies.

ER visits for asthma demonstrated a more than twofold increase in 2014, an effect that was exaggerated in females, in adults aged $\geq 40$ years and in Dene people. There was no increase in ER visits for combined respiratory diagnoses in 2014 compared with 2012-2013 (SIR (95\% CI) : 1.08 $(0.95,1.22)$ _ (table 3$)$. Visits for pneumonia increased by $57 \%$ (SIR (95\% CI): 1.57 (1.21, 2.00)), and were more common in males, in people aged $<40$ years and in Inuit people. Both ER visits and inpatient admissions for pneumonia were significantly increased in children under five. ER visits for asthma and pneumonia dropped in 2015 compared with the 2014 peak (table 3). There was no change in cardiac ER visits in 2014.

\section{DISCUSSION}

\section{Statement of principal findings}

Air quality in Yellowknife was poor in the summer of 2014: the 24-hour mean $\mathrm{PM}_{2.5}$ was fivefold higher compared with the previous years, it was above the WHO recommended threshold for more than $50 \%$ of days and it reached a peak of $320.3 \mu \mathrm{g} / \mathrm{m}^{3}$ in early August. A $10 \mu \mathrm{g} / \mathrm{m}^{3}$ increase in $\mathrm{PM}_{2.5}$ was associated with an $11 \%$ increase in asthmarelated ER visits, a $6 \%$ increase in pneumonia-related ER visits and an $11 \%$ increase in COPD-related hospital admissions. An examination of outcomes in the presence of a severe wildfire season (2014) compared with previous seasons showed an increase in health service use (ie, outpatient salbutamol dispensations increased by $45 \%$; primary care visits for cough, asthma and pneumonia increased; and ER visits for asthma doubled). Some impacts were enhanced in subgroups such as young children and Indigenous populations. There was no increase in cardiac ER visits nor cardiac hospital admissions.

\section{Explanation of the findings in relation to other studies}

The $11 \%$ increase in ER visits for asthma per $10 \mu \mathrm{g} /$ $\mathrm{m}^{3}$ increase in $\mathrm{PM}_{2.5}$ seen here was high compared with similar studies: in 2013, Yao et al found a 3\% increase in asthma visits per $10 \mu \mathrm{g} / \mathrm{m}^{3}$ of $\mathrm{PM}_{2.5}$ (1.10 (95\% CI: 1.00, 1.21) for $30 \mu \mathrm{g} / \mathrm{m}^{3}$ increase in $\left.\mathrm{PM}_{2.5}\right),{ }^{23}$ while in 2016 , the same group found a $6 \%$ increase in asthma visits per $10 \mu \mathrm{g} / \mathrm{m}^{3}$ over a fire season where the mean daily $\mathrm{PM}_{25}$ was $10.2 \mu \mathrm{g} / \mathrm{m}^{3}$ on extreme fire days, which is lower than our median daily mean $\mathrm{PM}_{2.5}$ of $30.8 \mu \mathrm{g} / \mathrm{m}^{3}{ }^{3}$. Henderson et alfound a $5 \%$ increase in the odds of an asthma-specific physician visit with a $10 \mu \mathrm{g} / \mathrm{m}^{3}$ increase in $\mathrm{PM}_{10}{ }^{24}$ The strong relationship between $\mathrm{PM}_{2.5}$ and asthma visits in our study may be associated with the fact that people with airways sensitive to air pollution may not initially have had medications on-hand given Yellowknife's excellent baseline air quality $\left(\mathrm{PM}_{2.5}=6 \mu \mathrm{g} / \mathrm{m}^{3}\right)$. The length and severity of the smoke exposure would also have worsened indoor air quality despite closed windows. ${ }^{10} 2526$ Incomplete compliance with public health advice to stay inside could have exacerbated health impacts, as a telephone survey of 441 Yellowknife residents in July 2014 reported that $76 \%$ of respondents had seen or heard air quality-related announcements asking them to stay inside, ${ }^{27}$ but only $48 \%$ had spent less time outdoors. ${ }^{27}$ Of those who did 
Table 3 Standardised incidence ratios for cardiorespiratory emergency room (ER) visits in extreme fire year 2014 compared with 2012-2013

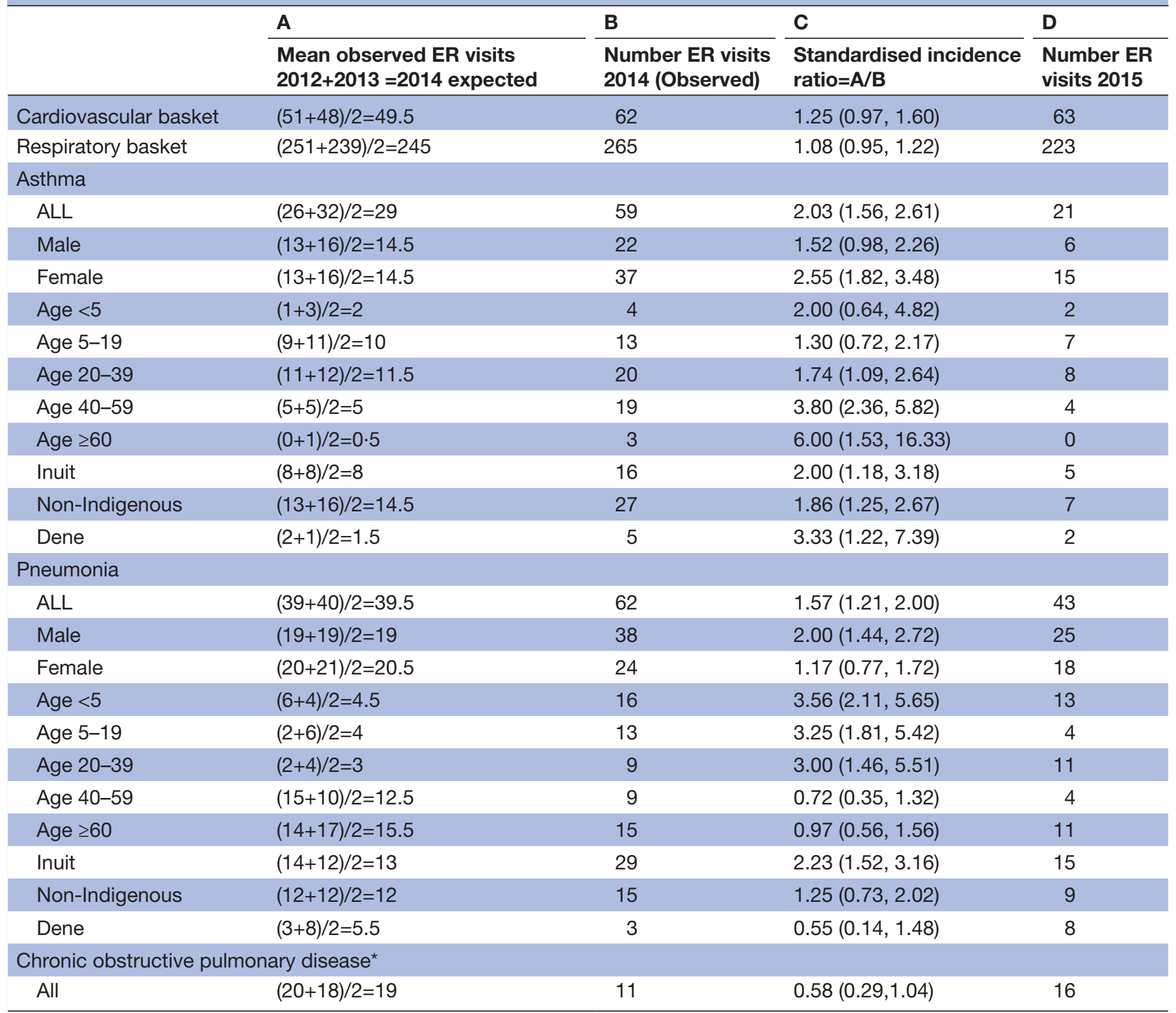

*Subgroup analyses were not performed for chronic obstructive pulmonary disease because case numbers were too small.

change their activities, almost one-fifth of respondents reported reduced strenuous aerobic activity or exercise, ${ }^{27}$ an undesirable adaptation given the health benefits of exercise. ${ }^{28}$ Analysis of 30 interviews conducted as part of the project and published elsewhere confirmed reduced physical activity, decreased feelings of wellness and a sense of isolation that one subject compared with being in jail. ${ }^{17}$ Many participants worried that the smoke and uncomfortable coping strategies could be a 'new normal' as a result of the changing climate. ${ }^{17}$

A stronger association between $\mathrm{PM}_{2.5}$ levels and $\mathrm{ER}$ visits for asthma was seen earlier in 2014 than later, which may be due to patients managing their symptoms at home in the latter part of the summer after having filled their prescriptions. Also, later in the summer, some residents spontaneously evacuated ${ }^{17}$ and leaders coordinated to offer free recreation opportunities in clean air shelters, which may have decreased symptoms related to outdoor exercise. $^{4}$

The risk of asthma-related ER visits and inpatient hospital admissions per $10 \mu \mathrm{g} / \mathrm{m}^{3}$ increase in $\mathrm{PM}_{2.5}$ was higher in men, but the relative change in asthma-related ER visits in the extreme fire year of 2014 compared with other years was enhanced among women. There was a stronger increase in the association between $\mathrm{PM}_{2.5}$ levels and ER visits for asthma, as well as a greater increase in ER visits, in people over 40 years of age. Previous studies have more often shown increased risk of wildfire-related asthma symptoms in women and in middle-aged and older adults. ${ }^{10}$ 
The effect of $\mathrm{PM}_{2.5}$ on pneumonia was pronounced among the very young, the elderly, males and Inuit people. Studies are inconsistent regarding differential effects of smoke by age, and smoke has been linked to poorer outcomes for people of lower socioeconomic status. ${ }^{1}$

$\mathrm{PM}_{2.5}$ was not related to ER visits for COPD and neither were there increased overall ER visits or hospital admissions for COPD. However, hospital admissions for COPD did increase by $11 \%$ per $10 \mu \mathrm{g} / \mathrm{m}^{3} \mathrm{PM}_{2.5}$, IRR (95\% CI): $1.11(1.02,1.20)$, an effect that was strongest in males, in Inuit and Dene people, and in individuals over 60. This is slightly higher than the $6.9 \%$ increase in COPD admissions per $10 \mu \mathrm{g} / \mathrm{m}^{3}$ of $\mathrm{PM}_{2.5}$ seen in a previous study, ${ }^{29}$ and is generally in line with increasing evidence of an association between wildfire smoke and COPD exacerbations.

Indigenous people in Canada experience pervasive health disparities due to 'the socioeconomic, environmental, and political contexts of their lives, a context inextricable from past and contemporary colonialism, ${ }^{30}$ Poor housing and increased exposure to environmental tobacco smoke may contribute to respiratory symptoms among Inuit populations in Canada, ${ }^{31}$ for example, and rates of lower respiratory tract infections have been shown to be elevated in children. ${ }^{32}$ Studies from Australia found a stronger relationship between $\mathrm{PM}_{10}$ levels and respiratory hospital admissions for Indigenous populations than non-Indigenous populations, ${ }^{33} 34$ with one study controlling for socioeconomic factors. ${ }^{16}$ Targeted interventions for high-risk populations could reduce impacts: a US study found a significant increase in clinic visits for respiratory symptoms on the Hoopa Valley National Indian reservation during a smoke episode, and noted that longer use of high-efficiency particulate air cleaners lessened symptoms, while the use of masks and evacuation did not. ${ }^{35}$

\section{Strengths and limitations of the study}

The NWT's excellent baseline air quality enables the influence of $\mathrm{PM}_{2.5}$ on respiratory outcomes to be more directly attributed to wildfires than in most studies. ${ }^{10}$ Also, the smoke exposure was particularly long and severe, making results useful for forward-looking adaptation planning in the Anthropocene. ${ }^{10}$ In addition, interview data from the larger project facilitated practical policy-relevant interpretations of our results. Limitations of the study were the inability to estimate the movement of people into or out of the study area over the course of the summer. Significant inflow of people via medivac planes or summertime tourism could have resulted in an overestimation of smoke-related impacts, while outflow of symptomatic people through self-evacuation to other regions, as reported during interviews, would result inthe study underestimating impacts. Given that impacts found were substantial, these may not have resulted in material change to conclusions or recommendations. Additionally, ethnicity information was not available for the small number of out-of-territory residents, meaning that rates for Indigenous and non-Indigenous subgroups may have been slightly higher or lower than shown here. Finally, there was a lack of data availability with regard to daily salbutamol dispensations, inpatient salbutamol use and daily clinic visits which limits detail in those areas; however, the trends are clear and in line with previous studies, and the multiple areas of the health system investigated in this study combined with the qualitative information gathered in the sister study provide an overall multifaceted evaluation of the health impacts of the summer of smoke on this subarctic population.

\section{Meaning of the study}

This severe, prolonged wildfire smoke exposure was associated with important respiratory impacts which may have been compounded by the difficulty of following public health messaging to stay inside due to the isolation, anxiety and decreased physical activity associated with being restricted indoors for a prolonged period. Healthy adaptation to extreme wildfires requires a planetary health-based holistic approach and improved coordination between public health, primary care, municipal and recreation leaders.

\section{Future studies}

There is a need to investigate the long-term impacts of acute, prolonged smoke exposure as well as differential impacts on at-risk populations. Further study is needed to evaluate multipronged health-systems approaches which include primary care-based attention to the needs of vulnerable populations involving proactive prescription of asthma-reliever medications and consideration for at-home air filtration ${ }^{28} 36$; public health-generated coordination to improve access to clean air shelters with recreation activities, and public health strategies that encourage populations to go outside during clean air windows and which attend to the complex interaction between smoke, isolation, climate change-related ecoanxiety and other mental health impacts. ${ }^{37}$

\section{Policy implications and future directions}

Severe wildfires have recently impacted communities from Canada to California to Australia and beyond, with increasing frequency and intensity predicted as global surface temperatures continue to rise. ${ }^{3}$ Climaterelated health effects impact all populations, but are likely to disproportionately affect communities living at the frontlines of rapid climate change, as well as those experiencing systemic racism, socioeconomic and health disparities, and/or the enduring effects of colonisation. This study demonstrates a need for active adaptation efforts to include attention to systemic factors and the social determinants of health, and to be more proactive, particularly with respect to investments with long time horizons, such as ensuring housing retrofits and and new builds have ventilation systems that are better able to maintain good indoor air quality in the face of wildfire smoke. The benefits of an adequate plan are multiple: 
interviewees in the study's sister armdescribed how uncertainty was associated with anxiety, whereas active preparation increased both physical safety and peace of mind. ${ }^{17}$ Primary care practitioners can identify smoke-susceptible individuals prior to wildfire season and ensure salbutamol prescriptions and air filters are available as appropriate. Public health practitioners can use satellite-based smoke forecasting to enhance adaptation interventions that include maximising opportunistic outdoor and accessible, well-ventilated indoor recreation and socialising opportunities. Climate-related health impacts are here, but healthier adaptation is possible.

\section{Author affiliations}

${ }^{1}$ Cumming School of Medicine, University of Calgary, Yellowknife, Northwest Territories, Canada

${ }^{2}$ School of Population and Public Health, The University of British Columbia, Vancouver, British Columbia, Canada

${ }^{3}$ School of Public Health and Health Systems, University of Waterloo, Waterloo, Ontario, Canada

${ }^{4}$ Northwest Territories Health and Social Services, Yellowknife, Northwest Territories, Canada

${ }^{5}$ Climate Change Initiatives, Ecology North, Yellowknife, Northwest Territories, Canada

${ }^{6}$ Jordanstone College of Art and Design, University of Dundee, Dundee, UK

${ }^{7}$ Labrador Institute, Memorial University of Newfoundland, Saint John's,

Newfoundland, Canada

${ }^{8}$ Dahdaleh Institute for Global Health Research, York University, Toronto, Ontario, Canada

\section{Twitter Courtney Howard @courtghoward}

Acknowledgements The authors would like to thank the Yellowknives Dene and the Ka'a'gee Tu First Nation for their partnership, particularly community coordinators Berna Martin, Nora Mackenzie and Melaine Simba. They would also like to thank the many health and allied health staff in the Northwest Territories for their help, Yellowknife pharmacies for collegially contributing their salbutamol dispensation data, Dr Susan Chatwood and the Institute for Circumpolar Health Research for their support, and Sarah Henderson for her advice and encouragement over the course of this study. Special thanks goes to the late Doug Ritchie for seeing that this study was possible and uniting our community to make it happen.

Contributors $\mathrm{CH}$ : Study conception and design, building of team, grant application, review of qualitative interview content, collection of quantitative data, study write-up and editing. CR: Study design, quantitative data analysis, study write-up and editing. WD: Qualitative data collection, qualitative data analysis, consultation on statistical analyses of quantitative data, review and editing of study write-up. KK: Study conception and design, grant application, collection of quantitative data and study editing. CS: Study conception and design, grant application, project management and community outreach, and study editing. PS: Study conception and design, grant application, interview design and qualitative information and study editing. AC: Study design, qualitative interview design and study editing. JO: Study design, grant application, consultation on quantitative analysis, review and editing of study write-up, and oversight of the project.

Funding This project was funded by a grant from Health Canada's Climate Change and Health Adaptation Program for First Nations and Inuit Communities (Grant Number $\mathrm{N} / \mathrm{A}$ ).

Competing interests None declared.

Patient consent for publication Not required.

Ethics approval This project was reviewed and approved by the Stanton Territorial Hospital Ethics Board and Wilfrid Laurier University Research Ethics Board (REB \#4700), as well as by the Aurora Research Institute (license numbers 15733; 15801).

Provenance and peer review Not commissioned; externally peer reviewed.

Data availability statement Data are available upon reasonable request. The data used in this study includes publicly available air monitoring data, and hospital, and clinic records that were requested from the relevant authorities. Pharmaceutical data was collected from local pharmacies. The data is held by the epidemiologist on our team and is available upon reasonable request.

Supplemental material This content has been supplied by the author(s). It has not been vetted by BMJ Publishing Group Limited (BMJ) and may not have been peer-reviewed. Any opinions or recommendations discussed are solely those of the author(s) and are not endorsed by BMJ. BMJ disclaims all liability and responsibility arising from any reliance placed on the content. Where the content includes any translated material, BMJ does not warrant the accuracy and reliability of the translations (including but not limited to local regulations, clinical guidelines, terminology, drug names and drug dosages), and is not responsible for any error and/or omissions arising from translation and adaptation or otherwise.

Open access This is an open access article distributed in accordance with the Creative Commons Attribution Non Commercial (CC BY-NC 4.0) license, which permits others to distribute, remix, adapt, build upon this work non-commercially, and license their derivative works on different terms, provided the original work is properly cited, appropriate credit is given, any changes made indicated, and the use is non-commercial. See: http://creativecommons.org/licenses/by-nc/4.0/.

ORCID iD

Courtney Howard http://orcid.org/0000-0001-6469-3561

\section{REFERENCES}

1 Reid CE, Brauer M, Johnston FH, et al. Critical review of health impacts of Wildfire smoke exposure. Environ Health Perspect 2016;124:1334-43.

2 Liu Y, Goodrick S, Heilman W. Wildland fire emissions, carbon, and climate: Wildfire-climate interactions. For Ecol Manage 2014;317:80-96.

3 Seidl R, Thom D, Kautz M, et al. Forest disturbances under climate change. Nat Clim Chang 2017;7:395-402.

4 Cameron PA, Mitra B, Fitzgerald M, et al. Black Saturday: the immediate impact of the February 2009 bushfires in Victoria, Australia. Med J Aust 2009;191:11-16.

5 McDermott BM, Lee EM, Judd M, et al. Posttraumatic stress disorder and general psychopathology in children and adolescents following a wildfire disaster. Can J Psychiatry 2005;50:137-43.

6 Papanikolaou V, Adamis D, Mellon RC, et al. Psychological distress following wildfires disaster in a rural part of Greece: a case-control population-based study. Int J Emerg Ment Health 2011;13:11-26.

7 Henderson SB, Johnston FH. Measures of forest fire smoke exposure and their associations with respiratory health outcomes. Curr Opin Allergy Clin Immunol 2012;12:221-7.

8 Elliott CT, Henderson SB, Wan V. Time series analysis of fine particulate matter and asthma reliever dispensations in populations affected by forest fires. Environ Health 2013;12:11.

9 Yao J, Eyamie J, Henderson SB. Evaluation of a spatially resolved forest fire smoke model for population-based epidemiologic exposure assessment. J Expo Sci Environ Epidemiol 2016;26:233-40.

10 Liu JC, Pereira G, Uhl SA, et al. A systematic review of the physical health impacts from non-occupational exposure to wildfire smoke. Environ Res 2015;136:120-32.

11 Black C, Gerriets JE, Fontaine JH, et al. Early life Wildfire smoke exposure is associated with immune dysregulation and lung function decrements in adolescence. Am J Respir Cell Mol Biol 2017;56:657-66.

12 Tan-Soo J-S, Pattanayak SK. Seeking natural capital projects: forest fires, haze, and early-life exposure in Indonesia. Proc Natl Acad Sci U $S$ A 2019;116:5239-45.

13 Haines A, Scheelbeek P, Abbasi K. Challenges for health in the Anthropocene epoch. BMJ 2019;364:1460.

14 Laing J, Binyamin J. Climate change effect on winter temperature and precipitation of Yellowknife, northwest territories, Canada from 1943 to 2011. Am J Clim Change 2013;02:275-83.

15 Government of the Northwest Territories. 2014 northwest territories fire season report, 2014.

16 Canadian Broadcasting Corporation. 2015 N.W.T. fire season was the 2nd-worst on record, 2015.

17 Dodd W, Scott P, Howard C, et al. Lived experience of a record wildfire season in the northwest territories, Canada. Can J Public Health 2018;109:327-37.

18 Government of the Northwest Territories. NWT Bureau of statistics, 2017. Available: https://www.statsnwt.ca/ [Accessed Sep 2017].

19 Bélanger D, Berry P, Bouchet V, et al. Human health in a changing climate: a Canadian assessment of vulnerabilities and adaptive capacity. Health Canada, 2008. 
20 Government of the Northwest Territories. Northwest territories air quality monitoring program, 2017. Available: http://aqm.enr.gov.nt. ca/ [Accessed 12 Dec 2017].

21 WHO. Factsheet ambient (outdoor) air quality and health, 2016. Available: http://www.who.int/mediacentre/factsheets/fs313/en/ [Accessed 13 Sep 2017].

22 Cates CJ, Welsh EJ, Rowe BH. Holding chambers (spacers) versus nebulisers for beta-agonist treatment of acute asthma. Cochrane Database Syst Rev 2013:CD000052.

23 Yao J, Brauer M, Henderson SB. Evaluation of a wildfire smoke forecasting system as a tool for public health protection. Environ Health Perspect 2013;121:1142-7.

24 Henderson SB, Brauer M, Macnab YC, et al. Three measures of forest fire smoke exposure and their associations with respiratory and cardiovascular health outcomes in a population-based cohort. Environ Health Perspect 2011;119:1266-71.

25 Barn PK, Elliott CT, Allen RW, et al. Portable air cleaners should be at the forefront of the public health response to landscape fire smoke. Environ Health 2016;15:116.

26 Dix-Cooper L. Evidence review: reducing time outdoors during wildfire smoke events: advice to stay indoors, advice to reduce outdoor physical activity and cancelling outdoor events. Vancouver: BC Centre for Disease Control, 2014.

27 Barry J. Summary report Yellowknife July 18-20, 2014. R. A. Malatest \& Associates Ltd, 2014.
28 Warburton DER, Bredin SSD. Health benefits of physical activity: a systematic review of current systematic reviews. Curr Opin Cardiol 2017;32:541-556.

29 Delfino RJ, Brummel S, Wu J, et al. The relationship of respiratory and cardiovascular hospital admissions to the southern California wildfires of 2003. Occup Environ Med 2009;66:189-97.

30 Greenwood M, de Leeuw S, Lindsay N. Challenges in health equity for Indigenous peoples in Canada. Lancet 2018;391:1645-8.

31 Kovesi T. Respiratory disease in Canadian first nations and Inuit children. Paediatr Child Health 2012;17:376-80.

32 Banerji A, Panzov V, Young M, et al. Hospital admissions for lower respiratory tract infections among infants in the Canadian Arctic: a cohort study. CMAJ Open 2016;4:E615-22.

33 Johnston FH, Bailie RS, Pilotto LS, et al. Ambient biomass smoke and cardio-respiratory hospital admissions in Darwin, Australia. BMC Public Health 2007;7:240.

34 Hanigan IC, Johnston FH, Morgan GG. Vegetation fire smoke, Indigenous status and cardio-respiratory hospital admissions in Darwin, Australia, 1996-2005: a time-series study. Environ Health 2008;7:42.

35 Mott JA, Meyer P, Mannino D, et al. Wildland forest fire smoke: health effects and intervention evaluation, Hoopa, California, 1999. West J Med 2002;176:157-62.

36 Koger SM, Leslie KE, Hayes ED. Climate change: psychological solutions and strategies for change. Ecopsychology 2011;3:227-35.

37 Cunsolo A, Ellis NR. Ecological grief as a mental health response to climate change-related loss. Nat Clim Chang 2018;8:275-81. 